\title{
Therapeutic outcomes and prognostic factors in unresectable gallbladder cancer treated with gemcitabine plus cisplatin
}

Min su You, Ji Kon Ryu* (D), Young Hoon Choi, Jin Ho Choi, Gunn Huh, Woo Hyun Paik, Sang Hyub Lee and Yong-Tae Kim

\begin{abstract}
Background: Gallbladder cancer (GBC) is likely to be diagnosed at progressive stages and shows a very poor prognosis. Combination therapy with gemcitabine and cisplatin (GEMCIS) has been widely used as first-line palliative chemotherapy for advanced GBC. This study was designed to investigate the efficacy of GEMCIS and identify prognostic factors in patients with unresectable GBC.

Methods: Patients with GBC who were treated with GEMCIS from January 2008 to June 2017 in a single tertiary hospital were included. All cases of GBC were diagnosed by pathologic findings and extent of the tumour was assessed by imaging tests. Combination chemotherapy consisted of cisplatin $25 \mathrm{mg} / \mathrm{m}^{2}$ and gemcitabine $1000 \mathrm{mg} / \mathrm{m}^{2}$ intravenously on days 1 and 8 every 3 weeks. To determine factors affecting prognosis, Kaplan-Meier survival analysis, log-rank test and the Cox proportional hazard regression linear model were used. All variables with $P<0.1$ in univariable analysis were included in the multivariable model.

Results: A total of 173 patients received a median of $5.3 \pm 4.4$ cycles of chemotherapy over $3.8 \pm 3.9$ months. Most of the patients (94.8\%) were stage IVB at the time of diagnosis and the most common site of metastasis was the liver (42. 8\%). Disease control rate was 59.5\%: 2 (1.2\%) patients with complete response, 26 (15.0\%) patients with partial response and 75 (43.4\%) patients with stable disease. Overall survival (OS) and progression-free survival were 8.1 (95\% confidence interval [CI], 7.1-10.2) and $5.6(95 \% \mathrm{Cl} 4.5-6.8)$ months, respectively. Multivariable regression model indicated that metastasis to liver (hazard ratio $[H R]=1.63,95 \% \mathrm{Cl} 1.11-2.40 ; P=0.013$ ), neutrophil-to-lymphocyte ratio (NLR) $\geq 3$ (HR 1. $65,95 \% \mathrm{Cl} 1.09-2.49 ; P=0.017)$, CEA $\geq 5 \mathrm{ng} / \mathrm{mL}$ (HR 1.50,95\% Cl 1.02-2.19; $P=0.038$ ), and CA19-9 $\geq 500 \mathrm{U} / \mathrm{mL}$ (HR 1.59, $95 \% \mathrm{Cl} 1.01-2.50 ; P=0.043$ ) were significantly associated with OS.
\end{abstract}

Conclusions: GEMCIS demonstrated a high disease control rate in patients with unresectable GBC. Factors independently related to OS were metastasis to liver, NLR $\geq 3, C E A \geq 5 \mathrm{ng} / \mathrm{mL}$ and CA19-9 $\geq 500 \mathrm{U} / \mathrm{mL}$.

Keywords: Gallbladder neoplasms, Gemcitabine, Cisplatin, Prognosis, Treatment outcome

\section{Background}

Gallbladder cancer (GBC) accounts for 80 to $90 \%$ of carcinomas in the biliary system. Cancer-related mortality among patients with GBC is increasing and expected to continue to increase until 2030 worldwide [1]. Since there are no specific symptoms in the early stage, GBC is often not diagnosed until advanced

\footnotetext{
* Correspondence: jkryu@snu.ac.kr

Department of Internal Medicine and Liver Research Institute, Seoul National University College of Medicine, Seoul National University Hospital, 101 Daehak-ro, Jongno-gu, Seoul 110-744, South Korea
}

stages. Surgery is the only curative treatment method; however, fewer than $10 \%$ of patients can undergo surgery, and $50 \%$ are found to have metastasis to lymph nodes at the time of diagnosis [2]. GBC has an abysmal prognosis and a median survival of 6 months if untreated [3].

Gemcitabine plus cisplatin (GEMCIS) is widely used as first-line chemotherapy for unresectable GBC based on a recent clinical trial showing favourable outcomes of the combination chemotherapy in patients with biliary tract cancer (BTC) [4]. Median overall survival

(c) The Author(s). 2019 Open Access This article is distributed under the terms of the Creative Commons Attribution 4.0 International License (http://creativecommons.org/licenses/by/4.0/), which permits unrestricted use, distribution, and 
(OS) and progression-free survival (PFS) were 11.7 and 8.0 months, respectively, in patients with BTC treated with GEMCIS [4]. However, in a more recent phase II clinical study that included only patients with unresectable GBC, median OS and PFS were 6.2 and 3.1 months, respectively [5]. Another study revealed that gallbladder cancer responds poorly to chemotherapy compared to other subtypes of biliary tract cancer [6]. Even though prognosis and response to chemotherapy in patients with GBC are different from those in patients with other subtypes of BTC, there is a lack of studies evaluating the efficacy of GEMCIS only in patients with GBC.

Several studies have identified various prognostic factors in patients with $\mathrm{GBC}$, including jaundice, metastasis to lymph nodes, and metastasis to liver [7-10]. Tumour markers, particularly carcinoembryonic antigen (CEA) and carbohydrate antigen 19-9 (CA19-9), are also well-known prognostic factors in GBC [11-13]. In addition, it has been shown that several variables of systemic inflammation response such as neutrophil-to-lymphocyte ratio (NLR) and platelet-to-lymphocyte ratio (PLR) have prognostic value in BTC [14-16]. However, previous studies are based on retrospective data from patients with BTC or $\mathrm{GBC}$ who were treated surgically, and prognostic factors in patients with unresectable GBC treated with GEMCIS are largely unknown.

Although GEMCIS is widely used in patients with advanced GBC based on the clinical trial in 2010, there may be differences in treatment efficacy between GBC and other subtypes of BTC. Moreover, previous studies regarding treatment efficacy and prognostic factors have focused mainly on patients with BTC or GBC who were treated primarily by surgery. Therefore, this study aimed to evaluate the efficacy of GEMCIS and identify prognostic factors in only patients with unresectable GBC.

\section{Methods}

\section{Study subjects}

Patients with unresectable GBC who were treated with GEMCIS at Seoul National University Hospital between January 2008 and June 2017 were analysed. All patients were diagnosed by pathologic confirmation and medical records of the patients were retrospectively reviewed. Extent of the disease was evaluated by contrast-enhanced computed tomography and 18F-fluoro-2-deoxy-D-glucose positron emission tomography with computed tomography scan.

Locations of regional lymph nodes included hepatic hilus along the common bile duct, hepatic artery, portal vein, and cystic duct, whereas involvement of lymph nodes around the celiac and superior mesenteric artery was considered distant metastatic disease [17]. A total of 186 patients were reviewed. Five patients who lacked baseline laboratory findings and eight patients with history of active cancer in another organ within 5 years were excluded (Fig. 1). In total, 173 patients were enrolled and analysed. This study was approved by the Institutional Review Board of the Seoul National University Hospital, Seoul, Korea (1703-004-834).

\section{Treatment and data collection}

Each cycle of combination chemotherapy consisted of cisplatin $25 \mathrm{mg} / \mathrm{m}^{2}$ and gemcitabine $1000 \mathrm{mg} / \mathrm{m}^{2}$ administered intravenously on days 1 and 8 every 3 weeks. The treatment was repeated until the occurrence of unacceptable toxicity, loss to follow-up, confirmation of disease progression, or death. Patients were followed up regularly and laboratory tests and imaging tests were periodically evaluated to assess therapeutic outcomes.

Demographic and clinical variables included age, gender, Eastern Cooperative Oncology Group (ECOG) performance status, body mass index, Charlson comorbidity index score, cancer stage, location of invasion and metastasis, previous therapeutic history, and total number of chemotherapy cycles. Laboratory variables included glomerular filtration rate, aspartate aminotransferase, alanine aminotransferase, total bilirubin, alkaline phosphatase, CEA, CA19-9, NLR, and PLR. NLR and PLR values were defined as the number of absolute neutrophils and platelets divided by the absolute lymphocyte count from samples of peripheral blood, respectively.

The primary endpoint was OS and the secondary endpoints were PFS and objective best overall tumour response. OS was defined as time from initiation of chemotherapy to the final date of follow-up or death from any cause. PFS was defined as time from initial treatment to the confirmation of disease progression or death. Mortality data were collected by the Ministry of the Interior and Safety. Best overall tumour response was assessed by contrast-enhanced CT scan based on the Response Evaluation Criteria in Solid Tumors (RECIST) 1.1 criteria [18]. Minimum duration for definition of stable disease was 1 month and tumour response was evaluated at intervals of two cycles.

\section{Statistical analysis}

Continuous variables with a normal distribution were expressed as the mean and standard deviation, while those with a non-normal distribution were summarised as the median and interquartile range (IQR). Categorical variables were presented with percentage, and the Pearson $\chi^{2}$ test was applied to determine differences between them. OS and PFS were calculated and compared using the Kaplan-Meier method and the log-rank test. To determine factors affecting prognosis, hazard ratio 


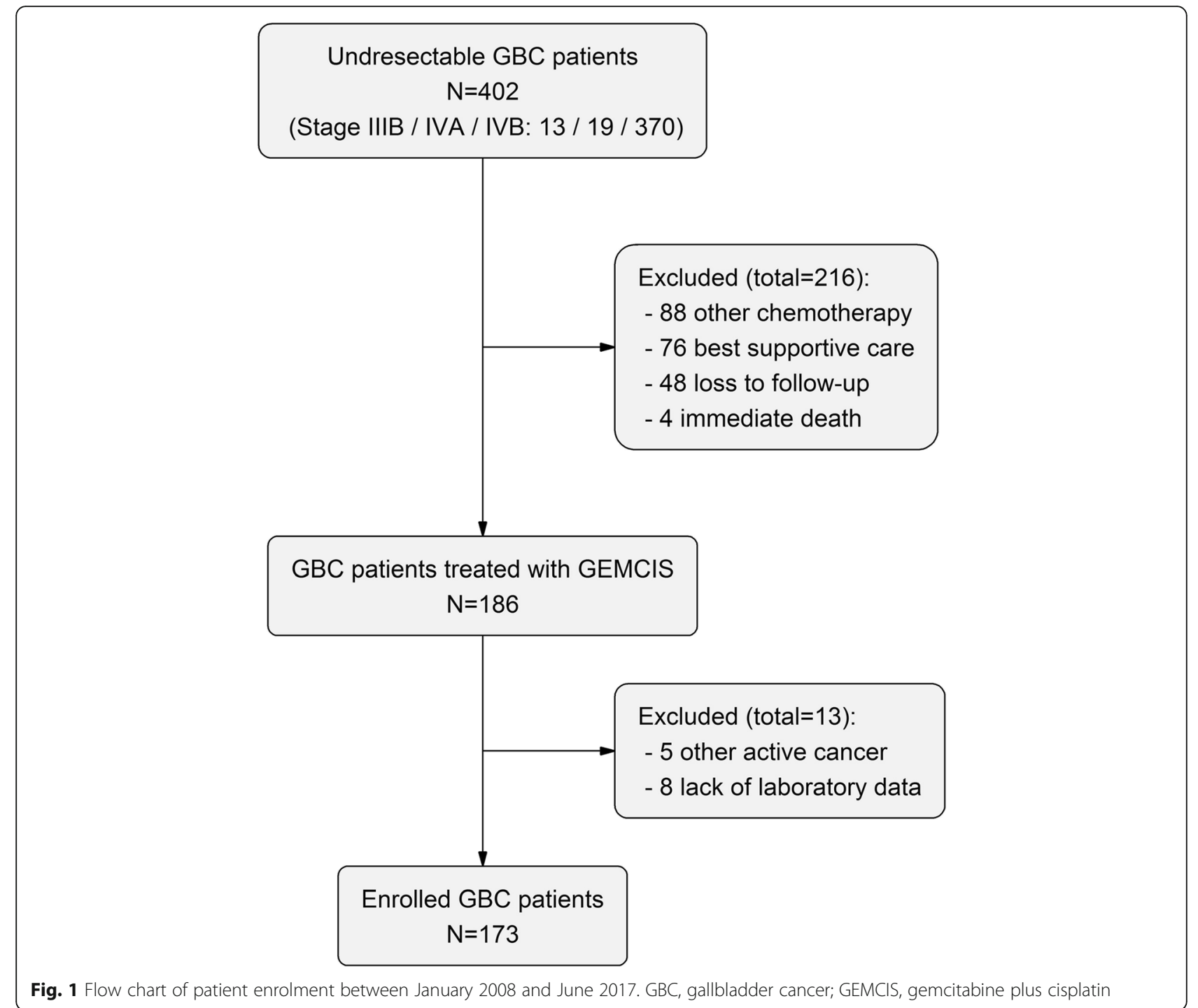

(HR) and 95\% confidence interval (CI) for OS and PFS were calculated using the Cox's proportional hazard regression model. Best cut-off values of NLR, PLR, and tumour markers were obtained using the Contal and O'Quigley method [19]. Multivariable analysis was performed including variables with $P<0.1$ in univariable analysis. Variables with $P<0.05$ were considered to indicate statistical significance. All statistical analyses were performed using $\mathrm{R}$ ver. 3.3.3 (Institute for Statistics and Mathematics, Vienna, Austria; http://www.R-project.org).

\section{Results}

\section{Clinical characteristics of patients}

Baseline characteristics are summarised in Table 1 . The most common site of adjacent cancer invasion was the liver $(27.2 \%)$, followed by the extrahepatic bile duct $(15.0 \%)$ and intestine (11.6\%). Invasion of hepatic artery and main portal vein was identified in 15 (8.7\%) and $11(6.4 \%)$ patients, respectively. Twenty-seven (15.6\%) patients were identified to have invasion to more than two organs. Most of the patients (94.8\%) were in stage IVB. Among the total patients, liver metastasis was identified in $74(42.8 \%)$ patients, followed by peritoneum in $46(26.6 \%)$ and lung in $29(16.8 \%)$ patients. There were two patients each with metastasis to abdominal wall and adrenal gland and one patient with metastasis to spleen. Metastasis to distant lymph node was found in $102(59.0 \%)$ patients, pericaval area in $58(33.6 \%)$, paraaortic area in $65(37.6 \%)$, and the area above the diaphragm in 31 (17.9\%) patients. Eighty-one $(46.8 \%)$ patients had metastasis to multiple lymph nodes.

Previous history of curative surgery was identified in 33 (19.1\%) patients, extended cholecystectomy in 23 (69.7\%), and simple cholecystectomy in 10 (30.3\%) patients. Median duration after surgery until recurrence 
Table 1 Baseline characteristics of all patients

\begin{tabular}{ll}
\hline Variables & $N=173$ \\
\hline Age (range) & $63.8(25.0-84.0)$ \\
Sex (female / male) & $86(49.7 \%) / 87(50.3 \%)$ \\
ECOG (0 / 1 / 2) & $36(20.8 \%) / 126$ \\
& $(72.8 \%) / 11(6.4 \%)$ \\
BMI & $23.0 \pm 2.8$ \\
Charlson comorbidity index & $8.0 \pm 1.4$ \\
Stage (IIIB / IVA / IVB) & $1(0.6 \%) / 8$ \\
& $(4.6 \%) / 164(94.8 \%)$
\end{tabular}

Invasion

$\begin{array}{ll}\text { Liver } & 47(27.2 \%) \\ \text { Extrahepatic bile duct } & 26(15.0 \%) \\ \text { Intestine } & 20(11.6 \%) \\ \text { Peritoneum } & 2(1.2 \%) \\ \text { Hepatic artery } & 15(8.7 \%) \\ \text { Main portal vein } & 11(6.4 \%)\end{array}$

Metastasis

$\begin{array}{ll}\text { Liver } & 74(42.8 \%) \\ \text { Peritoneum } & 46(26.6 \%) \\ \text { Lung } & 29(16.8 \%) \\ \text { Bone or muscular system } & 14(8.1 \%) \\ \text { Distant lymph node } & 102(59.0 \%) \\ \text { Previous history } & \\ \text { Biliary drainage } & 49(28.3 \%) \\ \text { Curative surgery } & 33(19.1 \%) \\ \text { Palliative chemotherapy } & 12(8.5 \%)\end{array}$

Baseline laboratory findings

WBC (cells/ $\mu \mathrm{L}$ )

CRP ( $\mathrm{mg} / \mathrm{dL})$

eGFR $\left(\mathrm{mL} / \mathrm{min} / 1.73 \mathrm{~m}^{2}\right)$

AST (IU/L)

ALT (IU/L)

ALP (IU/L)

Bilirubin, total $(\mathrm{mg} / \mathrm{dL})$

CEA $(\mathrm{ng} / \mathrm{mL})$

CA 19-9 (U/mL)

NLR

PLR

$6540.0 \pm 5192.4$

$3.5 \pm 4.0$

$92.8 \pm 23.1$

$40.3 \pm 40.3$

$44.2 \pm 50.8$

$183.7 \pm 174.9$

$1.5 \pm 2.4$

$68.6 \pm 247.7$

$2676.9 \pm 6783.1$

$4.2 \pm 3.4$

$189.0 \pm 95.0$

ECOG Eastern Cooperative Oncology Group, BMI body mass index, WBC white blood cell, CRP C-reactive protein, eGFR estimated glomerluar filtration rate, AST aspartate aminotransferase, ALT alanine aminotransferase, $A L P$ alkaline phosphatase, CEA carcinoembryonic antigen, CA 19-9 carbohydrate antigen 19-9, NLR neutrophil-to-lymphocyte ratio, PLR platelet-to-lymphocyte ratio

was 10.0 (95\% CI 7.79-16.34) months. Median OS in patients with previous history of curative surgery and those without was 7.8 (95\% CI 6.7-10.0) and 11.1 (95\% CI 6.715.1) months, respectively $(P=0.202)$. Twelve patients had previous history of palliative chemotherapy; nine patients received fluoropyrimidine-based chemotherapy, and the other three patients had palliative concurrent chemoradiation therapy with fluoropyrimidine. Among 44 (25.4\%) patients who underwent biliary drainage due to malignant hilar obstruction before the initial chemotherapy, 35 (79.5\%) were treated with endoscopic retrograde biliary drainage and 9 (20.5\%) with percutaneous transhepatic biliary drainage.

\section{Treatment outcomes}

Treatment data during GEMCIS chemotherapy are summarised in Table 2. The median follow-up duration was $8.6 \pm 7.1$ months. Based on 147 (85.0\%) deaths, OS was 8.1 (95\% CI 7.1-10.2) and PFS was 5.6 (95\% CI 4.5-6.8) months (Fig. 2). Disease control was achieved in $103(59.5 \%)$ patients; $2(1.2 \%)$ with complete response (CR), 26 (15.0\%) with partial response, and 75 (43.4\%) with stable disease. Of the two patients with the best CR response, one patient who initially had metastasis to peritoneum remained in $\mathrm{CR}$ until the last

Table 2 Treatment data and efficacy of GEMCIS in unresectable gallbladder cancer

\begin{tabular}{ll}
\hline Variables & $N=173$ \\
\hline Treatment duration, months & $3.8 \pm 3.9$ \\
Total cycle & $5.3 \pm 4.4$ \\
OS, months $(95 \% \mathrm{Cl})$ & $8.1(7.1-10.2)$ \\
PFS, months $(95 \% \mathrm{Cl})$ & $5.6(4.5-6.8)$ \\
Best response & \\
CR & $2(1.2 \%)$ \\
PR & $26(15.0 \%)$ \\
SD & $75(43.4 \%)$ \\
PD & $48(27.7 \%)$ \\
NE & $22(12.7 \%)$ \\
ORR (CR + PR) & $28(16.2 \%)$ \\
DCR (CR + PR + SD) & $103(59.5 \%)$ \\
Number of cycles & \\
1 & $38(22.0 \%)$ \\
2 & $31(18.0 \%)$ \\
3 & $8(4.7 \%)$ \\
4 & $16(9.3 \%)$ \\
5 & $10(5.8 \%)$ \\
7 & $18(10.5 \%)$ \\
9 & $6(3.5 \%)$ \\
$\geq 10$ & $14(8.1 \%)$ \\
\hline
\end{tabular}

GEMCIS gemcitabine plus cisplatin, OS overall survival, PFS progression-free survival, $C l$ confidence interval, $C R$ complete response, $P R$ partial response, $S D$ stable disease, $P D$ progressive disease, $N E$ not evaluable, $O R R$ overall response rate, $D C R$ disease control rate 


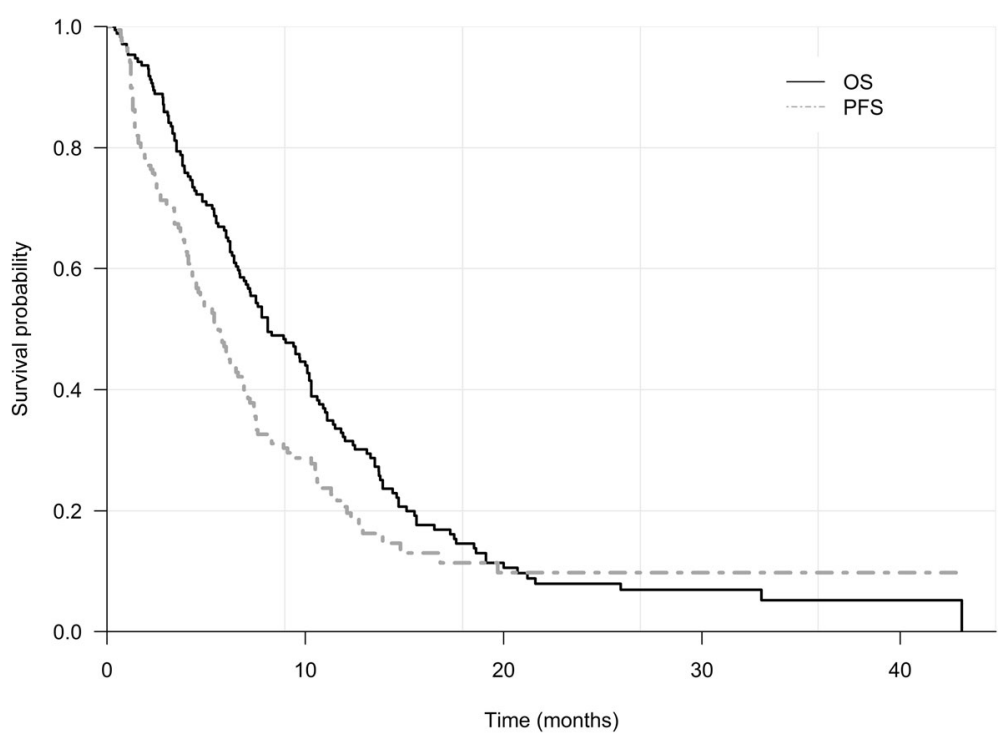

Fig. 2 Overall survival (OS) and progression-free survival (PFS) of patients treated with gemcitabine plus cisplatin

date of follow-up and the other patient showed progression of disease with recurrence at the lung 10 months after the last chemotherapy.

Patients received a total of $5.3 \pm 4.4$ cycles of chemotherapy during $3.8 \pm 3.9$ months. A subsequent line of chemotherapy was feasible in 73 (42.2\%) patients: fluoropyrimidine-based therapy in 57 (32.9\%), clinical trial in $14(8.1 \%)$, gemcitabine single therapy in $2(1.5 \%)$, and concurrent chemoradiation therapy with fluoropyrimidine in $1(0.7 \%)$ patient. Median overall survival of the patients who underwent further lines of palliative chemotherapy was 10.2 (95\% CI 8.1-12.0) months, which was not significantly different from that of patients who did not receive a subsequent line of chemotherapy (median OS 6.4 months; 95\% CI 4.4-9.7; $P=0.086)$.

With regard to hematological grade $3 / 4$ toxicity, neutropaenia was most commonly noted $(28.6 \%)$, followed by anaemia (19.3\%) and thrombocytopaenia (17.1\%). Febrile neutropaenia occurred in eight patients (4.6\%). Deep vein thrombosis and pulmonary thromboembolism developed in $18(10.4 \%)$ and $9(5.2 \%)$ patients, respectively. Transaminase increased to more than 3 times the upper limits of normal in $27(15.6 \%)$ patients during treatment. Nausea and/or vomiting (20.2\%) and diarrhoea (6.9\%) frequently occurred. Severe non-haematological toxicity of grade 3 or greater was infrequent and included diarrhoea $(n=3)$, nausea/vomiting $(n=2)$, and neuropathy $(n=1)$.

\section{Prognostic factors}

In univariable analysis, several variables showed $P<0.1$ (Table 3): ECOG 2 (HR 1.86; 95\% CI 0.94-3.68; $P=0.074$ ), invasion to liver (HR 1.47; 95\% CI 1.02-2.12; $P=0.040$ ), metastasis to liver (HR 1.72; 95\% CI 1.23-2.41; $P=0.002$ ), metastasis to bone and muscle (HR 2.03; 95\% CI 1.143.61; $P=0.016$ ), total bilirubin $\geq 1.5 \mathrm{X}$ upper limit of normal (HR 1.77; 95\% CI 1.21-2.58; $P=0.003$ ), transaminase $\geq 1.5 \mathrm{X}$ upper limit of normal (HR 1.53; 95\% CI $1.07-2.18 ; P=0.019), \mathrm{NLR} \geq 3$ (HR 2.34; 95\% CI $1.66-$ 3.29; $P<0.001$ ), PLR $\geq 190$ (HR 1.77; 95\% CI 1.27-2.47; $P<0.001), C E A \geq 5 \mathrm{ng} / \mathrm{mL}$ (HR 1.87; 95\% CI 1.33-2.63; $P<0.001$ ), and CA $19-9 \geq 500 \mathrm{U} / \mathrm{mL}(\mathrm{HR} 2.28 ; 95 \% \mathrm{CI}$ $1.61-3.23 ; P<0.001)$.

The results of multivariable analysis are listed in Table 4 . In the final multivariable analysis, independent prognostic factors for poor OS were metastasis to liver (HR 1.63; 95\% CI 1.11-2.40; $P=0.013$ ), NLR $\geq 3$ (HR 1.65; 95\% CI 1.09-2.49; $P=0.017$ ), CEA $\geq 5 \mathrm{ng} / \mathrm{mL}$ (HR $1.50 ; 95 \%$ CI $1.02-2.19 ; P=0.038)$ and CA19-9 $\geq 500$ (HR 1.59; 95\% CI 1.01-2.50; $P=0.043$ ). Median OS in patients with liver metastasis was 6.2 (95\% CI 5.3-10.0, $P=0.001$ ) months (Fig. 3). Hypertransaminasemia was identified in 26/74 (35.1\%) patients in patients with liver metastasis, which was not significantly different from the incidence in patients without liver metastasis $(P=0.346)$. When classified by baseline NLR $\geq 3$, CA $19-9 \geq 500 \mathrm{U} /$ $\mathrm{mL}$ and CEA $\geq 5 \mathrm{ng} / \mathrm{mL}$, median OS was 6.2 (95\% CI $4.8-$ 7.8, $P<0.001$ ), 5.5 (95\% CI 4.1-7.6, $P<0.001)$ and 6.5 (95\% CI 5.0-8.1, $P<0.001$ ) months, respectively (Fig. 4).

\section{Discussion}

The aim of this study was to examine the efficacy of GEMCIS and identify prognostic factors in unresectable GBC. In this study, GEMCIS showed a high disease control rate, and liver metastasis, NLR, CEA, and CA 19-9 were significantly associated with prognosis. Overall, this study showed a median OS of 8.6 months, 
Table 3 Univariable analysis of possible factors affecting overall survival

\begin{tabular}{|c|c|c|c|c|}
\hline & Number of patients (\%) & Median OS, months (95\% Cl) & $\mathrm{HR}(95 \% \mathrm{Cl})$ & $P$ value \\
\hline \multicolumn{5}{|l|}{ Age } \\
\hline$<65$ & $90(52.0 \%)$ & $10.1(7.6-11.4)$ & 1.00 & \\
\hline$\geq 65$ & $83(48.0 \%)$ & $7.2(6.0-10.0)$ & $1.28(0.92-1.78)$ & 0.138 \\
\hline \multicolumn{5}{|l|}{ Sex (female/ male) } \\
\hline Female & $86(49.7 \%)$ & $10.1(7.8-12)$ & 1.00 & \\
\hline Male & $87(50.3 \%)$ & $7.1(5.5-10.1)$ & $1.22(0.88-1.69)$ & 0.234 \\
\hline \multicolumn{5}{|l|}{ ECOG } \\
\hline $0-1$ & $164(94.8 \%)$ & $8.1(7.1-10.3)$ & 1.00 & \\
\hline 2 & $9(5.2 \%)$ & 7.5 (2.8-NE) & $1.86(0.94-3.68)$ & 0.074 \\
\hline \multicolumn{5}{|l|}{ BMl } \\
\hline$>25$ & $136(78.6 \%)$ & $7.8(6.6-9.7)$ & 1.00 & \\
\hline$\geq 25$ & $37(21.4 \%)$ & $11.9(7.1-15.1)$ & $0.79(0.53-1.18)$ & 0.255 \\
\hline \multicolumn{5}{|l|}{ Stage } \\
\hline IIIB/IVA & $9(5.2 \%)$ & 7.2 (2.1-NE) & 1.00 & \\
\hline IVB & $164(94.8 \%)$ & $8.1(7.1-10.3)$ & $0.68(0.35-1.35)$ & 0.272 \\
\hline \multicolumn{5}{|l|}{ Charlson comorbidity index } \\
\hline$<9$ & $110(63.6 \%)$ & $9.7(7.8-11.0)$ & 1.00 & \\
\hline$\geq 9$ & $63(36.4 \%)$ & $6.4(4.4-10.2)$ & $1.23(0.87-1.72)$ & 0.237 \\
\hline \multicolumn{5}{|l|}{ Local invasion } \\
\hline Liver & $47(27.2 \%)$ & $7.7(6.6-11.4)$ & $1.47(1.02-2.12)$ & 0.040 \\
\hline Extrahepatic bile duct & $26(15.0 \%)$ & $6.5(5.0-11.9)$ & $1.06(0.67-1.67)$ & 0.812 \\
\hline Intestine & $20(11.6 \%)$ & 8.6 (5.0-NE) & $0.79(0.47-1.34)$ & 0.386 \\
\hline Peritoneum & $2(1.2 \%)$ & 10.5 (2.3-NE) & $0.94(0.23-3.82)$ & 0.933 \\
\hline Hepatic artery & $15(8.7 \%)$ & 6.4 (5.0-NE) & $1.12(0.63-1.98)$ & 0.699 \\
\hline Portal vein & $11(6.4 \%)$ & 5.9 (2.3-NE) & $1.17(0.6-2.31)$ & 0.643 \\
\hline \multicolumn{5}{|l|}{ Metastasis site } \\
\hline Liver & $74(42.8 \%)$ & $6.2(5.3-10.0)$ & $1.72(1.23-2.41)$ & 0.002 \\
\hline Peritoneum & $46(26.6 \%)$ & $6.5(4.2-10.1)$ & $1.25(0.87-1.82)$ & 0.229 \\
\hline Lung & $29(16.8 \%)$ & $7.2(5.4-15.6)$ & $0.85(0.54-1.34)$ & 0.487 \\
\hline Bone or muscular system & $14(8.1 \%)$ & $5.1(3.3-13.1)$ & $2.03(1.14-3.61)$ & 0.016 \\
\hline Distant lymph node & $102(59.0 \%)$ & $8.3(6.5-10.9)$ & $1.10(0.79-1.54)$ & 0.560 \\
\hline \multicolumn{5}{|l|}{ Total bilirubin } \\
\hline$\leq 1.5 \times$ ULN & $130(75.1 \%)$ & $9.7(7.8-11.0)$ & 1.00 & \\
\hline$>1.5 \times$ ULN & $43(24.9 \%)$ & $5.3(3.7-9.5)$ & $1.77(1.21-2.58)$ & 0.003 \\
\hline \multicolumn{5}{|l|}{ Transaminase } \\
\hline$\leq 1.5 \times$ ULN & $120(69.4 \%)$ & $9.7(7.8-11.5)$ & 1.00 & \\
\hline$>1.5 \times$ ULN & $53(30.6 \%)$ & $6.2(4.5-9.7)$ & $1.53(1.07-2.18)$ & 0.019 \\
\hline \multicolumn{5}{|l|}{ NLR } \\
\hline$\leq 3$ & $75(43.4 \%)$ & $12.4(10.2-14.6)$ & 1.00 & \\
\hline$>3$ & $98(56.6 \%)$ & $6.2(4.8-7.8)$ & $2.34(1.66-3.29)$ & $<0.001$ \\
\hline \multicolumn{5}{|l|}{ PLR } \\
\hline$<190$ & 102 (59.0\%) & $10.3(9.4-13.7)$ & 1.00 & \\
\hline$\geq 190$ & $71(41.0 \%)$ & $6.6(5.6-8.1)$ & $1.77(1.27-2.47)$ & 0.001 \\
\hline
\end{tabular}

CEA, ng/mL 
Table 3 Univariable analysis of possible factors affecting overall survival (Continued)

\begin{tabular}{|c|c|c|c|c|}
\hline & Number of patients (\%) & Median OS, months (95\% Cl) & $\mathrm{HR}(95 \% \mathrm{Cl})$ & $P$ value \\
\hline$<5$ & $103(59.5 \%)$ & $10.3(7.8-13.1)$ & 1.00 & \\
\hline$\geq 5$ & $70(40.5 \%)$ & $6.5(5.0-8.1)$ & $1.87(1.33-2.63)$ & $<0.001$ \\
\hline \multicolumn{5}{|c|}{ CA 19-9, U/mL } \\
\hline$<500$ & $114(65.9 \%)$ & $10.7(9.0-13.3)$ & 1.00 & \\
\hline$\geq 500$ & $59(34.1 \%)$ & $5.5(4.1-7.6)$ & $2.28(1.61-3.23)$ & $<0.001$ \\
\hline
\end{tabular}

OS overall survival, HR hazard ratio, ECOG Eastern Cooperative Oncology Group, BMI body mass index, NLR neutrophil-to-lymphocyte ratio, PLR platelet-tolymphocyte ratio, CEA carcinoembryonic antigen, CA 19-9 carbohydrate antigen 19-9, NE not estimable, ULN upper limit of normal

Table 4 Multivariable analysis by Cox regression model

\begin{tabular}{llll}
\hline Variable & Number & HR $(95 \% \mathrm{Cl})$ & $P$-value \\
\hline ECOG & 164 & 1.00 & \\
$0-1$ & 9 & $0.79(0.34-1.85)$ & 0.586 \\
2 & & & \\
Invasion to liver & 126 & 1.00 & 0.648 \\
No & 47 & $0.91(0.59-1.39)$ & \\
Yes & & & \\
Metastasis to liver & 99 & 1.00 & 0.013 \\
No & 74 & $1.63(1.11-2.40)$ &
\end{tabular}

Metastasis to bone and muscle

$\begin{array}{cclc}\text { No } & 159 & 1.00 & \\ \text { Yes } & 14 & 1.78(0.93-3.42) & 0.081 \\ \text { NLR } & & & \\ <3 & 75 & 1.00 & \\ \geq 3 & 98 & 1.65(1.09-2.49) & 0.017 \\ \text { PLR } & & & \\ <190 & 102 & 1.00 & \\ \geq 190 & 71 & 1.19(0.79-1.77) & 0.405\end{array}$

Total bilirubin

$\leq 1.5 \times \cup L N$

$>1.5 \times$ ULN

130

1.00

$1.56(0.95-2.55)$

0.077

Transaminase

$\leq 1.5 \times \cup L N$

$>1.5 \times$ ULN

120

1.00

CEA, ng/mL

$<5$

53

$0.92(0.59-1.45)$

0.723

$<5-103$

1.00

$\geq 5$

70

$1.50(1.02-2.19)$

1.00

$\begin{array}{lll}<500 & 114 & 1.00 \\ \geq 500 & 59 & 1.59(1.01-2.50)\end{array}$

ECOG Eastern Cooperative Oncology Group, CEA carcinoembryonic antigen, CA 19-9 carbohydrate antigen 19-9, NLR neutrophil-to-lymphocyte ratio, $P L R$ platelet-to-lymphocyte ratio, CEA carcinoembryonic antigen, CA 19-9 carbohydrate antigen 19-9, ULN upper limit of normal in general accordance with the previous phase II study in Japan regarding the efficacy of GEMCIS in 14 patients with unresectable GBC [4]. On the other hand, previous study which investigated efficacy of GEMCIS in patients with BTC reported the median OS of 11.7 months, suggesting that prognosis is worse in GBC than that in other subtypes of BTC $[4,5]$. Moreover, in this study, there were 76 patients who were not able to undergo chemotherapy, 48 patients loss to follow-up, and 4 patients who died immediately after GBC diagnosis. Since GEMCIS was clinically applied in patients with generally good performance, the actual prognosis of unresectable GBC is likely to be worse than the prognosis reported in this study.

The gallbladder has no serosal layer near the liver and its perimuscular connective tissue is in direct contact with the liver. Subsequently, invasion of GBC into liver is very common and liver involvement is known to be associated with poor prognosis $[3,6]$. In this study, however, liver invasion was not an independent prognostic factor, as opposed to previous studies which mostly included patients with resectable GBC. The discrepancy may stem from the different inclusion criteria. Meanwhile, metastasis to liver, which occurs via portal tracts, is common in advanced GBC and indicates poor prognosis $[9,20,21]$. These findings coincide well with the results of our study that identified liver metastasis as an independent poor prognostic factor. Currently, there are no standard treatment methods regarding liver metastasis although several chemotherapy regimens can be considered in patients with liver metastasis on the basis of the National Comprehensive Cancer Network Clinical Practice Guidelines [22]. Because of the absence of the specific standard treatment guidelines, further studies are required to evaluate best treatment modalities for liver metastasis.

It is well known that CEA and CA19-9 are helpful not only in diagnosis, but also in predicting prognosis of GBC [11, 12]. Wang et al. [13] reported that CA199 plays an important role as an independent prognostic factor in GBC. Likewise, Park et al. [23] recently reported that CEA independently predicts prognosis in patients with metastatic BTC. Consistent with previous 


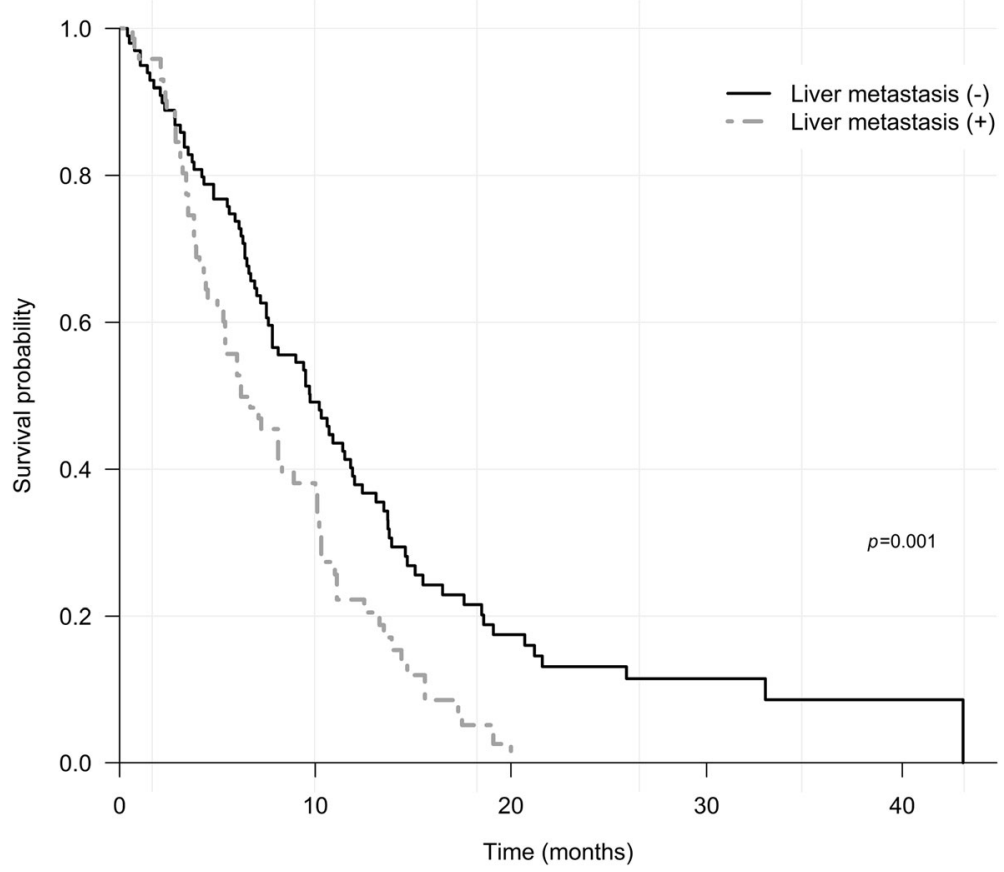

Fig. 3 Kaplan-Meier curves of overall survival according to liver metastasis

studies [23, 24], the results of our study demonstrated that baseline CA 19-9 and CEA level were independent prognostic markers.

The association of NLR with prognosis has been widely studied in patients with BTC $[15,16,23,25]$. Zhang et al. [14] found that patients with NLR $\geq 2.61$ had a worse prognosis than those with NLR $<2.61$ in a study of 316 patients with GBC treated with surgery. In our study, multivariate analysis revealed NLR $\geq 3$ as an independent risk factor for poor OS, which was in general accordance with previous studies. The correlation between NLR and prognosis can be explained by the fact that neutrophils secrete vascular endothelial growth factors and several cytokines to promote tumour development and proliferation whereas lymphocytes play a crucial role in tumour defence by inducing cytotoxic cell death [26-28].
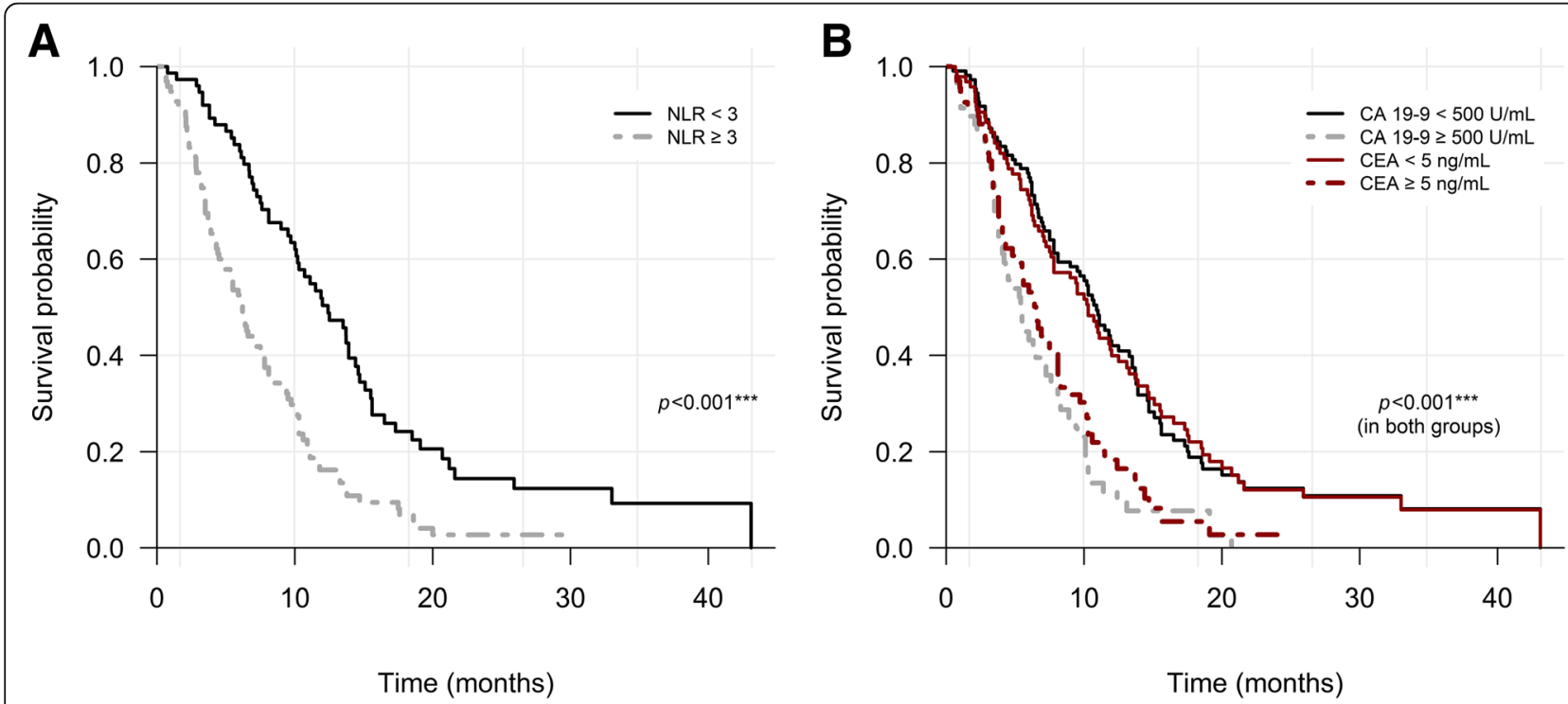

Fig. 4 Kaplan-Meier curves of overall survival according to groups based on the results of multivariable analysis and log-rank test. a Classified by $\mathrm{NLR} \geq 3$. b Classified by CA19-9 $\geq 500 \mathrm{U} / \mathrm{mL}$ and CEA $\geq 5 \mathrm{ng} / \mathrm{mL}$. NLR, neutrophil-to-lymphocyte ratio; CA 19-9, carbohydrate antigen 19-9; CEA, carcinoembryonic antigen 
Pro-inflammatory and pro-angiogenic cytokines are known to be important causative factors in the development of BTC and cytokine-based therapies have been studied [29]. It is expected that the NLR will play an important role in the prediction of prognosis in future development of therapies targeting cancer-associated inflammation.

A limitation of our study is that it is based on retrospective data from a single tertiary care center. Although the results of our study showed a somewhat longer OS than the previous phase II clinical trial in Japan, there may be several confounding factors stemming from the retrospective study design that affect the results of analysis. Second, since the present study was conducted without a control group, careful interpretation and further validation is needed. Despite these limitations, clinical data from this study are helpful because there are very few studies examining the efficacy of GEMCIS combination chemotherapy and prognostic factors specifically in patients with unresectable GBC.

Third, the cut-off values of the tumour markers, NLR, and PLR were estimated based on a relatively small sample size. Although these cut-off values were found to be statistically significant, a large-scale prospective study to determine the ideal cut-off value is needed. Another limitation is that direct invasion of GBC to surrounding tissues was based on imaging findings because we selected only patients with unresectable disease. Diagnostic aspects of imaging tests in evaluating direct invasion of tumour to surrounding tissues may be less sensitive or less accurate than pathologic examination accompanied by surgical resection. Nevertheless, due to the development of recent imaging techniques, the sensitivity and specificity of the diagnosis by computed tomography are as high as 99 and $76 \%$, respectively, and the interpretation of the results of this study seems to be reasonable [30].

\section{Conclusions}

In conclusion, GEMCIS is an effective regimen in patients with unresectable GBC. The prognostic factors identified in this study might help accurate patient risk stratification and decision of a proper treatment plan.

\section{Abbreviations}

BTC: Biliary tract cancer; CA19-9: Carbohydrate antigen 19-9;

CEA: Carcinoembryonic antigen; Cl: Confidence interval; ECOG: Eastern Cooperative Oncology Group; GBC: Gallbladder cancer; GEMCIS: Gemcitabine plus cisplatin; HR: Hazard ratio; IQR: Interquartile range; NLR: Neutrophil-tolymphocyte ratio; OS: Overall survival; PFS: Progression-free survival;

PLR: Platelet-to-lymphocyte ratio

\section{Acknowledgements}

This study was supported by the Seoul National University College of Medicine Research Fund (2018).
Funding

Not applicable.

\section{Availability of data and materials}

The datasets used and/or analysed during the current study are available from the corresponding author on reasonable request.

\section{Authors' contributions}

Conception and design by JKR; collection and assembly of data by MY and JHC; provision of study materials or patients by YHC, SHL and YTK; data analysis and interpretation by GH and WHP; manuscript writing by MY and JKR. All authors read and approved the final manuscript.

\section{Ethics approval and consent to participate}

This study was approved by Institutional Review Board of the Seoul National University Hospital, Seoul, Korea (1703-004-834). Patients were not required to give informed consent to the study because the analysis used anonymous clinical data that were obtained after each patient agreed to treatment by written consent.

\section{Consent for publication}

Not applicable.

\section{Competing interests}

The authors declare that they have no competing interests.

\section{Publisher's Note}

Springer Nature remains neutral with regard to jurisdictional claims in published maps and institutional affiliations.

Received: 21 May 2018 Accepted: 12 December 2018

Published online: 05 January 2019

\section{References}

1. Are C, Ahmad H, Ravipati A, Croo D, Clarey D, Smith L, Price RR, Butte JM, Gupta S, Chaturvedi A, et al. Global epidemiological trends and variations in the burden of gallbladder cancer. J Surg Oncol. 2017:115(5):580-90.

2. Sheth S, Bedford A, Chopra S. Primary gallbladder cancer: recognition of risk factors and the role of prophylactic cholecystectomy. Am J Gastroenterol. 2000;95(6):1402-10.

3. Hundal R, Shaffer EA. Gallbladder cancer: epidemiology and outcome. Clin Epidemiol. 2014;6:99-109.

4. Valle J, Wasan H, Palmer DH, Cunningham D, Anthoney A, Maraveyas A, Madhusudan S, Iveson T, Hughes S, Pereira SP, et al. Cisplatin plus gemcitabine versus gemcitabine for biliary tract cancer. N Engl J Med. 2010; 362(14):1273-81.

5. Hirooka Y, Ishikawa T, Kawashima H, Ohno E, Nonogaki K, Kanamori A, Hirai T, Uchida H, Shirai O, Ishikawa H, et al. Prospective multicenter phase II study of gemcitabine plus cisplatin in patients with unresectable gallbladder cancer. Cancer Chemother Pharmacol. 2017:80(1):119-25.

6. Qu K, Liu S-N, Chang H-L, Liu C, Xu X-S, Wang R-T, Zhou L, Tian F, Wei J-C, Tai M-H, et al. Gallbladder Cancer: a subtype of biliary tract Cancer which is a current challenge in China. Asian Pac J Cancer Prev. 2012;13(4):1317-20.

7. Chen C, Geng Z, Shen H, Song H, Zhao Y, Zhang G, Li W, Ma L, Wang L. Long-term outcomes and prognostic factors in advanced gallbladder Cancer: focus on the advanced T stage. PLoS One. 2016;11(11):e0166361.

8. Amini N, Kim Y, Wilson A, Margonis GA, Ethun CG, Poultsides G, Tran T, Idrees K, Isom CA, Fields RC, et al. Prognostic implications of lymph node status for patients with gallbladder Cancer: a multi-institutional study. Ann Surg Oncol. 2016;23(9):3016-23.

9. Yamamoto Y, Sugiura T, Ashida R, Okamura Y, Ito T, Uesaka K. Indications for major hepatectomy and combined procedures for advanced gallbladder cancer. Br J Surg. 2017;104(3):257-66.

10. Yang XW, Yuan JM, Chen JY, Yang J, Gao QG, Yan XZ, Zhang BH, Feng S, Wu MC. The prognostic importance of jaundice in surgical resection with curative intent for gallbladder cancer. BMC Cancer. 2014;14:652.

11. Gourgiotis S, Kocher HM, Solaini L, Yarollahi A, Tsiambas E, Salemis NS. Gallbladder cancer. Am J Surg. 2008;196(2):252-64.

12. Yu T, Yu H, Cai X. Preoperative prediction of survival in resectable gallbladder cancer by a combined utilization of CA 19-9 and carcinoembryonic antigen. Chin Med J. 2014;127(12):2299-303. 
13. Wang YF, Feng FL, Zhao XH, Ye ZX, Zeng HP, Li Z, Jiang XQ, Peng ZH. Combined detection tumor markers for diagnosis and prognosis of gallbladder cancer. World J Gastroenterol. 2014;20(14):4085-92.

14. Zhang L, Wang R, Chen W, Xu X, Dong S, Fan H, Liu C. Prognostic significance of neutrophil to lymphocyte ratio in patients with gallbladder carcinoma. HPB (Oxford). 2016;18(7):600-7.

15. Chen Q, Dai Z, Yin D, Yang LX, Wang Z, Xiao YS, Fan J, Zhou J. Negative impact of preoperative platelet-lymphocyte ratio on outcome after hepatic resection for intrahepatic cholangiocarcinoma. Medicine (Baltimore). 2015; 94(13):e574.

16. Kitano Y, Yamashita Yl, Yamamura K, Arima K, Kaida T, Miyata T, Nakagawa S, Mima K, Imai K, Hashimoto D, et al. Effects of preoperative neutrophil-tolymphocyte and platelet-to-lymphocyte ratios on survival in patients with extrahepatic cholangiocarcinoma. Anticancer Res. 2017;37(6):3229-37.

17. Amin M, Edge S, Greene F, Byrd DR, Brookland RK, Washington MK, Gershenwald JE, Compton CC, Hess KR, Sullivan DC, Jessup JM, Brierley JD, Gaspar LE, Schilsky RL, Balch CM, Winchester DP, Asare EA, Madera M, Gress DM, Meyer LR, editors. AJCC Cancer staging manual. New York: 8th Springer; 2017.

18. Eisenhauer EA, Therasse P, Bogaerts J, Schwartz LH, Sargent D, Ford R, Dancey J, Arbuck S, Gwyther S, Mooney M, et al. New response evaluation criteria in solid tumours: revised RECIST guideline (version 1.1). Eur I Cancer. 2009;45(2):228-47.

19. Contal C, O'Quigley J. An application of changepoint methods in studying the effect of age on survival in breast cancer. Comput Stat Data Anal. 1999; 30(3):253-70.

20. Ogura Y, Tabata M, Kawarada Y, Mizumoto R. Effect of hepatic invasion on the choice of hepatic resection for advanced carcinoma of the gallbladder: histologic analysis of 32 surgical cases. World J Surg. 1998;22(3):262-6 discussion 266-267.

21. Lin H-T, Liu G-J, Wu D, Lou J-Y. Metastasis of primary gallbladder carcinoma in lymph node and liver. World J Gastroenterol. 2005;11(5):748-51.

22. NCCN Clinical Practice Guidelines in Oncology. Hepatobiliary Cancers (v.3. 2018). 2018, https://www.nccn.org/professionals/physician_gls/pdf/ hepatobiliary.pdf. Accessed 2 Oct 2018.

23. Park HS, Park JS, Chun YJ, Roh YH, Moon J, Chon HJ, Choi HJ, Park JS, Lee DK, Lee SJ, et al. Prognostic factors and scoring model for survival in metastatic biliary tract Cancer. Cancer Res Treat. 2017;49(4):1127-39.

24. Lee DW, Im SA, Kim YJ, Yang Y, Rhee J, Na II, Lee KH, Kim TY, Han SW, Choi IS, et al. CA19-9 or CEA decline after the first cycle of treatment predicts survival in advanced biliary tract Cancer patients treated with S-1 and cisplatin chemotherapy. Cancer Res Treat. 2017;49(3):807-15.

25. McNamara MG, Templeton AJ, Maganti M, Walter T, Horgan AM, McKeever L, Min T, Amir E, Knox JJ. Neutrophi//lymphocyte ratio as a prognostic factor in biliary tract cancer. Eur J Cancer. 2014;50(9):1581-9.

26. Kusumanto $\mathrm{YH}$, Dam WA, Hospers GA, Meijer C, Mulder NH. Platelets and granulocytes, in particular the neutrophils, form important compartments for circulating vascular endothelial growth factor. Angiogenesis. 2003;6(4):283-7.

27. Balkwill F, Mantovani A. Inflammation and cancer: back to Virchow? Lancet. 2001;357(9255):539-45.

28. Mantovani A, Allavena P, Sica A, Balkwill F. Cancer-related inflammation. Nature. 2008;454(7203):436-44.

29. Sahu S, Sun W. Targeted therapy in biliary tract cancers-current limitations and potentials in the future. J Gastrointest Oncol. 2017;8(2):324-36.

30. Li B, Xu XX, Du Y, Yang HF, Li Y, Zhang Q, Xiao DM, Huang YY, Meng J, Wang WX. Computed tomography for assessing resectability of gallbladder carcinoma: a systematic review and meta-analysis. Clin Imaging. 2013;37(2):327-33.

Ready to submit your research? Choose BMC and benefit from:

- fast, convenient online submission

- thorough peer review by experienced researchers in your field

- rapid publication on acceptance

- support for research data, including large and complex data types

- gold Open Access which fosters wider collaboration and increased citations

- maximum visibility for your research: over $100 \mathrm{M}$ website views per year

At BMC, research is always in progress.

Learn more biomedcentral.com/submissions 